\title{
Vegetation index behavior (EVI) in burnt areas at Chapada dos Veadeiros National Park - PNCV/GO
}

\author{
Maxwell Antonio da Penha Araujo ${ }^{1 *}$, Noely Vicente Ribeiro ${ }^{1}$ \\ 1 Laboratório de Processamento de Imagens e Geoprocessamento, Universidade Federal de Goiás \\ (LAPIG/UFG) \\ *e-mail: maxwell.antonio7@gmail.com
}

\begin{abstract}
Wildfires are some of Cerrado characteristics, having an important function on vegetation maintainment, although they also promotes negative environmental impacts. Seeking to understand the vegetation's behavior with wildfires, this study aims to analyse the vegetation index / Enhanced vegetation index in burnt areas between 2006 and 2010, and the relation between these burnt areas with morphopedological compartments within the PNCV territory, including its $10 \mathrm{~km}$ damping area. For the EVI analysis Landsat images from the study period were used, totalizing 115 EVI cutouts. The morphopedological compartmentation is resulted from a comparative analysis and associated to the physical variables: geology, geomorphology, hipsometry, declivity and soils. The procedures were executed in GIS, used to intersect and associate the themes, resulting in I, II, III and IV morphopedological compartments. It was observed, with EVI data, that the large wildfires precedent results to the difference between the EVIs from burnt and not burnt areas were closer to zero, tending to positive values, what might mean that the areas which suffered wildfires were with a similar vegetation to the areas which didn't suffer or even with bigger green leaf areas, proving the use of this biomass to the fire spread. This pattern is also evident on the results obtained after the huge fires, with more negative results, what displays that the burnt areas could be recent marks, or with regenerating vegetation. The III and IV compartments were the most striked ones by wildfires. About $76 \%$ of compartment IV area was burned during the studying period, whilst compartment III burned area reached 57\%. These compartments are formed by areas whose altitude, relief and natural vegetation variations are larger. The morphopedological compartmentation might be one of the tools for the choice of priority areas to wildfire prevention, and the EVI discloses the vegetation as one of the main factors to fire spreading, highlighting the significance of management in these areas.
\end{abstract}

Keywords: wildfires, enhanced vegetaion index and morphopedological compartments. 